\title{
A Giant Asymptomatic Submandibular Salivary Gland Calculus Reported At Bahria University Dental Hospital.
}

Daud Mirza, Syed Ahmed Omer, Muhammad Shahrukh Khan Sadiq, Zubair Ahmad Abbasi, Mamoora Arsalan, Zahra Karim, Jouhra Khan, Saima Mazhar

ABSTRACT:

Sialolithiasis is a common salivary gland disease which has highest predilection rate in submandibular followed by parotid and sublingual glands. It results in mechanical obstruction of the salivary gland duct. The unique anatomy of the submandibular gland duct facilitates the deposition of mineral salts and leads to the formation of stones. We are presenting a unique case of submandibular calculus which was completely asymptomatic. On 2nd day after a mandibular incisor tooth extraction, patient presented with some hard object in her mouth. The stone was removed intraorally through the duct opening under local anaesthesia.

Key Words: Sialolith, Submandibular gland, Calculus, Stay suture

\section{INTRODUCTION:}

Salivary gland calculus (stone) also known as Sialolith, is the second most common salivary gland pathology which accounts for $30 \%$ after mumps. The incidence rate varies with respect to gender, but higher predilection is seen in males as compared to females ${ }^{1}$. According to an estimate, sialolithiasis affects 12 in 1000 among elderly individuals and it is rarely seen in children ${ }^{2,3}$. The sialoliths in vast majority of cases are frequently found in submandibular glands that constitute $92 \%$ of overall cases. It is due to its unique anatomic position and long tortuous duct with a narrow orifice compared to the main portion of the duct $t^{4}$. Along with these factors, alkaline nature of saliva which is rich in mucin may also contribute to the formation of salivary stones. On the other hand, the parotid and sublingual salivary gland sialolith accounts for $6 \%$ and $2 \%$ respectively. ${ }^{1,5,6,7}$ Salivary stones may vary in size ranging

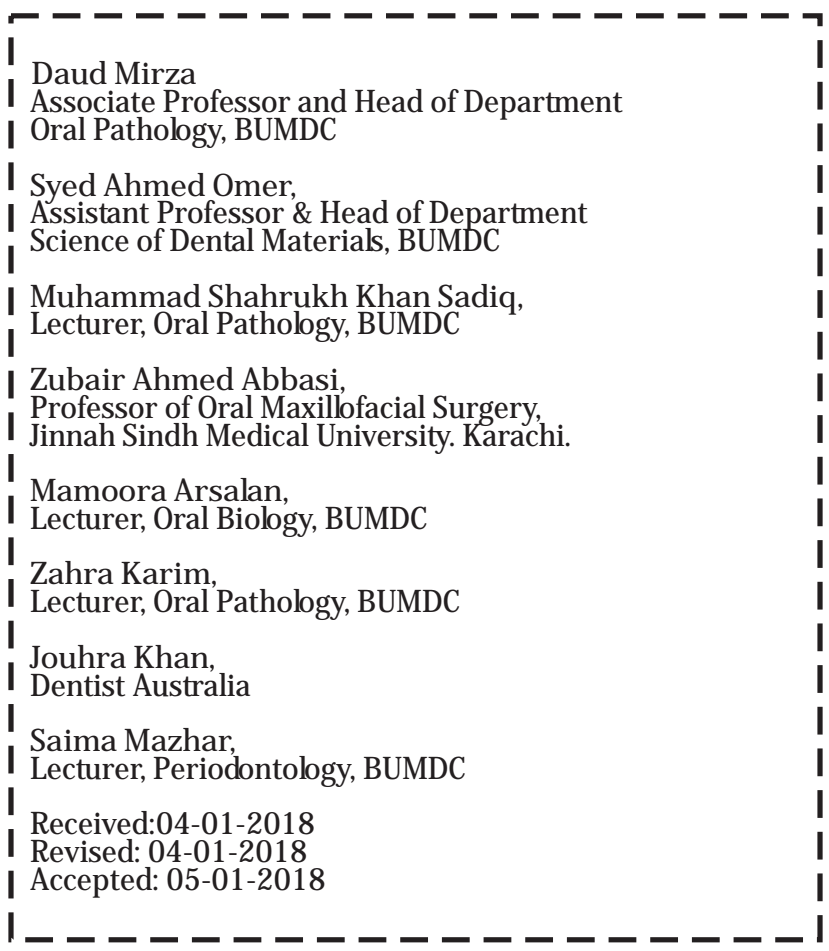

from few millimetres to several centimetres. Giant salivary stones are those calculi that are greater than the size of $15 \mathrm{~mm}$ and also are an extremely rare finding ${ }^{8,9,10}$.

The present case report describes a patient presenting with unusual and long submandibular sialolith and highlights the diagnostic and current treatment modalities.

\section{CASE REPORT:}

A 65 year old female presented to the Oral \& Maxillofacial Surgery (OMFS) department of Bahria University Dental Hospital, Karachi with complaint of pain in lower incisor tooth. Medical history was taken which revealed patient was hypertensive and diabetic. Both systemic conditions were in control level. Oral examination revealed that tooth $31,35,16,45,46,47$ was already extracted due to periodontal disease. However, tooth 41 was extracted a day before because of tooth mobility. On the next day, patient came up with the perception of a tooth portion left, that was impinging on the dorsum of tongue. Again thorough clinical examination was done which showed palpable calculus was attached with the orifice of submandibular duct behind the lingual aspect of extracted 41 tooth as shown in Figure 1. Furthermore, the patient did not report of any pain during meal timings nor she was aware about the calculus.

The periapical $\mathrm{x}$-ray was taken but this radiographic view was least helpful in determining the presence of remaining calculi in the duct. Also, it had already been emerging from the orifice of submandibular gland duct (Figure 2). Consent was taken from the patient for the removal of calculi. After taking consent, local anaesthesia (Lidocaine $2 \%, 1: 100,000$ ) was administered in the area at the floor of mouth. A stay suture was passed in the distal portion of the duct and a horizontal incision was given on the dorsal surface of the duct, along the long axis of the duct, in the floor of mouth. The calculus was removed from the orifice which was later measured with the help of measuring scale. It was $25 \mathrm{~mm}$ in length $(2.5 \mathrm{~cm})$ as demonstrated in Fig: 4 and 5. No bleeding was encountered. Stay 


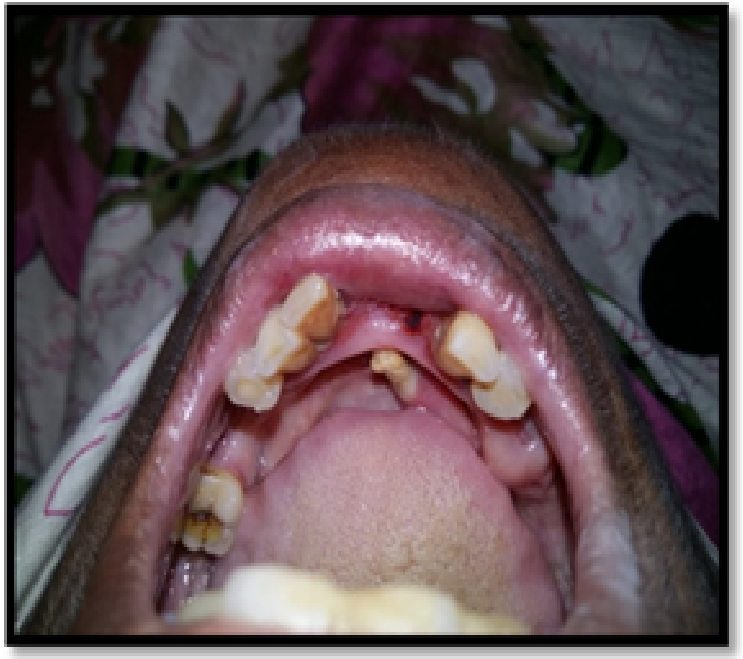

Figure 1: Submandibular calculi in the duct

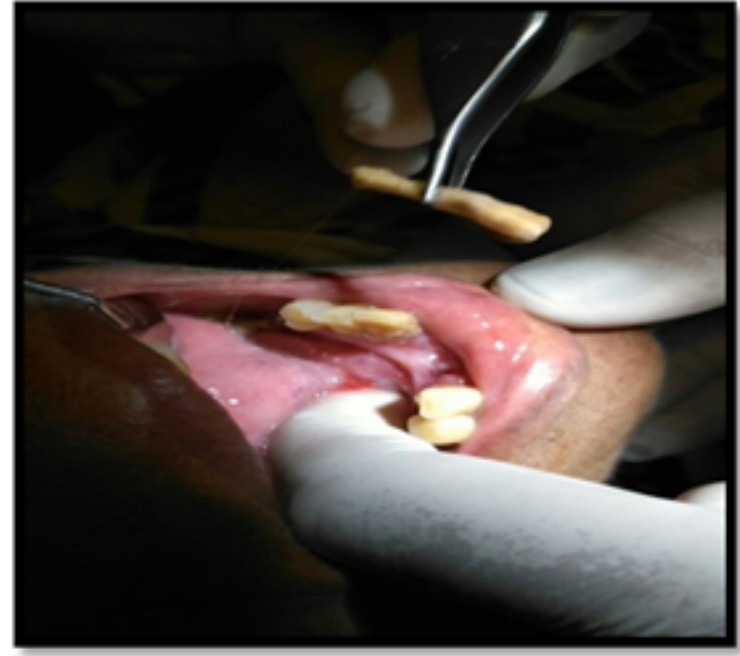

Figure 2: Calculi removed from the orifice

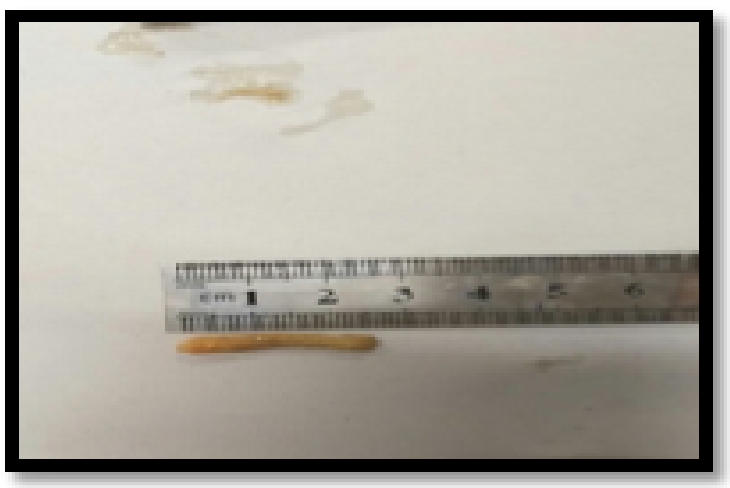

Figure 3: Measurement of calculi

suture was removed and the sub-mandibular gland was milked to observe unobstructed salivary flow. The patient was instructed to maintain oral hygiene. Analgesics were prescribed and follow-up was advised.

\section{DISCUSSION:}

Sialolithiasis is a pathological condition of salivary gland which is more frequent in males as compared to females ${ }^{24}$. Literature has shown the peak incidence between the age of 3rd to 6th decade of life. Salivary stones are rare occurrence in children ${ }^{25}$. The exact etiology is unknown and various theories have been proposed to understand the mechanism behind sialothiasis ${ }^{11}$. The first theory states that the presence of excreted intracellular microcalculi becomes a nidus for calcification. The repeated calcification leads to the formation of stone $\mathrm{e}^{12,13}$. The second theory holds that, the retrograde migration of microbes, food debris and other substances from the oral cavity into the duct of the salivary glands is the main cause for calculi production ${ }^{14}$. The calculi are made up of a mixture of different calcium phosphates (mainly hydroxy-apatite and carbonate-apatite) together with an organic matrix, mucin bacteria and desquamated epithelial cells. Once a small amount of calculi is formed, it allows lamellar crystallizations to occur due to precipitation of calcium salts. With passage of time it gradually increases in size. A small size sialolith can expel in mouth due to salivary secretions. Thorough history and clinical examination plays vital role in the diagnosis of submandibular sialolithiasis. Other signs and symptoms like pain and swelling, increases particularly during meal timings. Complete obstruction due to sialolith causes constant pain and swelling; pus may be seen draining from the duct and signs of systemic infection may be present $2,5,16,17,18,19$. Other methods which can be used is bimanual palpation of the floor of the mouth in a posterior to anterior direction, that reveals a palpable stone in a large number of cases of submandibular calculi formation ${ }^{6}$. Other imaging technique, also useful for the diagnosis of sialolithiasis is occlusal radiograph that reveals radiopaque stones ${ }^{20}$. Sialography is effective in patients showing signs of sialadenitis related to radiolucent stones or deep submandibular/ parotid stones. The clinician should keep in mind that sialography is contraindicated in those patients who have acute infection or insignificant patient contrast allergy ${ }^{6,9}$. 
The treatment modalities of sialolith vary from patient to patient depending upon the involved gland, size and location of the stone. Generally, conservative techniques are advised for small sialoliths, while the surgical removal is indicated for giant calculus ${ }^{21,22,23}$. Ultrasonography should be considered first choice examination in diagnosis of salivary calculi. Sialo-magnetic resonance imaging is a recent, non-invasive diagnostic procedure for the accurate anatomical position of gland and its duct ${ }^{26}$.

\section{CONCLUSION:}

Salivary gland calculus with enormous size in our case report is rarely found in individuals. It was asymptomatic in our case. Surgical procedure has been used to restore salivary flow from the duct to make the patient comfortable. Investigation was done in order to avoid misdiagnosis. The patient should be educated to stay hydrated as well as maintain oral hygiene to avoid the recurrence.

\section{REFERENCES:}

1. Andretta M, Tregnaghi A, Prosenikliev V, Staffieri A. Current opinions in sialolithiasis diagnosis and treatment. Acta Otorhinolaryngol Ital. 2005;25:145-149.

2. Siddiqui SJ. Sialolithiasis: an unusually large submandibular salivary stone. British Dental Journal: 2002;193, 89-91.

3. Leung A K, Choi M C, Wagner GA. Multiple sialolths and a sialolith of unusual size in the submandibular duct. Oral Surg, Oral Med, Oral Path, Oral Radiol, Endo 1999; 87: 331333.

4. Escudier MPMcGurk M Symptomatic sialoadenitis and sialolithiasis in the English population: an estimate of the cost of hospital treatment. Br Dent J.1999;186:463-466.

5. Pollack Jr CV, Severance Jr HW Sialolithisis: case studies and review.J Emergency Medicine 1990; 8: 561-565.

6. Williams MF Sialolithisis Otolaryngologic Clinics of North America 1999; 32: 819-834.

7. El Deeb M, Holte N, Gorlin RJ. Submandibular salivary gland sialoliths perforated through the oral floor. Oral Surg Oral Med Oral Pathol 1981;51:134-9.

8. McKenna JP Bostock DJ McMenamin PG Sialolithiasis. Am Fam Physician 1987; 36: 119-25

9. Ali Iqbal, Anup K. Gupta, Subodh S. Natu, and Atul K. Gupta et al. Unusually large sialolith of Wharton's duct: Contemp Clin Dent 2012;3(Suppl 2): 185-7

10. Soares EC, Costa FW, Pessoa RM, Bezerra (2009) Giant salivary calculus of the submandibular gland. Otolaryngol Head Neck Surg 140: 1289.

11. Ashby RA, The chemistry of sialoliths: stones and their homes. In: Norman JED, McGurk M, eds. Color Atlas and Text of the Salivary Glands: Diseases, Disorders, and Surgery. London, England: Mosby-Wolfe; 1995.
12. Epivatianos A,Harrison JD, Dimitriou T, Ultrastructural and histochemical observations on microcalculi in chronic submandibular sialadenitis. J Oral Pathol.1987;16:514517.

13. Harrison JD, Epivatianos A, Bhatia SN, Role of microliths in the aetiology of chronic submandibular sialadenitis: a clinicopathological investigation of 154 cases. Histopathology.1997;31:237-251.

14. Marchal F, Kurt AM, Dulguerov P, Lehmann W Retrograde theory in sialolithiasis formation. Arch Otolaryngol Head Neck Surg.2001;127:66-68.

15. Seifert G Mann W, Kastenbauer E, Sialolithiasis (1992) In: Naumann HH, Helms J, Herberhold C, Kastenbauer E eds. Oto-Rhino-Laryngology, 2 [in German]. Stuttgart, Germany: Georg Thieme Verlag 729-32.

16. Batori M, Mariotta G, Chatelou H, et al. Diagnostic and surgicalo management of submandibular gland sialolithiasis: Report of a stone of unusual size. Eur Rev Med Pharmacol Sci. 2005;9:67-8.

17. Lustmann J, Regev E, Melamed Y, Sialolithiasis: a survey on 245 patients and a review of the literature. Int J Oral Maxillofac Surg.1990;19:135-138.

18. Cawson RA, Gleeson MJ, Eveson JW, Sialadenitis. In: Pathology and Surgery of the Salivary Glands. Oxford, England: Isis Medical Media; 1997:33-63.

19. Zk J, Constantinidis J, Kydles S, Hornung J, Iro H. Clinical and diagnostic findings in sialolithiasis. HNO. 1999;47(11):963-9.

20. Isacsson $\mathrm{G}$ Isberg $\mathrm{A}$, Haverling $\mathrm{M}$ et al. Salivary calculi and chronic sialadenitis of the submandibular gland: A radiographic and histological study. Oral Surg 1984; 58: 622-627.

21. Cardoso AMR, Hosto O. Sialolito gigante em ducto de Warton: relato de caso clínico. R Bras Ci Saude. 2012;16(3):459-62.

22. Ferreira EF, Manzi FR. Diagnóstico por imagem de sialolito na glândula parótida utilizando radiografias convencionais. Arq Bras Odontol. 2010;6(1):25-32.

23. Landgraf H, Assis, AF, Klüppel LE, Oliveira CF, Gabrielli MAC. Extenso sialolito no ducto da glândula submandibular: relato de caso. Rev Cir Traumatol Buco-Maxilo-Fac. 2006;6(2): 29-34

24. Haubrich J. Klinik der nicht Tumor bedingten Erkrankungen der Speicheldrusen. Arch Otorhinolaryngol 1976;213:159.

25. Capaccio P, Torretta S, Ottaviani F, Sambataro G Pignataro L. Modern management of obstructive salivary diseases. Acta Otorhinolaryngologica Italica. 2007;27(4):161-172.

26. Andretta M, Tregnaghi A, Prosenikliev V, Staffieri A. Current opinions in sialolithiasis diagnosis and treatment. Acta Otorhinolaryngologica Italica. 2005;25(3):145-149. 